\title{
A short review of the photomechanical effect in azo-containing amorphous (glassy) polymers
}

\author{
J. Konieczkowska ${ }^{1 *}$, K. Bujak ${ }^{2}$, E. Schab-Balcerzak ${ }^{1}$ \\ ${ }^{1}$ Centre of Polymer and Carbon Materials, Polish Academy of Sciences, 34 M. Curie-Sklodowska Str., 41-819 Zabrze, \\ Poland \\ ${ }^{2}$ Institute of Chemistry, University of Silesia, Szkolna 9, 40-006 Katowice, Poland
}

Received 27 August 2020; accepted in revised form 29 October 2020

\begin{abstract}
The photomechanical effect has been studied so far mainly in elastomers, but recently more and more publications, in which this effect is studied for other materials too, so-called glassy or amorphous polymers (in particular polyimides), have appeared. This mini-review describes the photomechanical effect in polyimides containing light-sensitive derivatives of azobenzene and, in some cases, for comparison, in polyamides and polystyrenes. The work aims to present the influence of chemical structure factors on the bending angle of free-standing polymer films and their long-term stability. We focused on aspects of polymer structure such as the content of azo-moieties, the flexibility of the backbone, kind of azobenzene attachment (covalent/non-covalent), degree of crystallinity, influence the intermolecular H-bonds. The paper should help in designing new amorphous azopolymers with properties tailored to specific applications.
\end{abstract}

Keywords: smart polymers, photomechanical effect, azopolyimides

\section{Introduction}

Light can be considered a clean stimulus that allows remote control without physical contact or a mechanical apparatus. It is attractive because it enables one to change the geometry and dipole moment of photoswitching molecules, causing macroscopic variations of molecularly organized structures by small perturbations. Azo-dyes being of azobenzene derivatives are very attractive systems for light-controlled applications in photonic, optoelectronic, and medical fields, etc. due to their easy trans-cis isomerization. Irradiation of azobenzenes upon UV-vis radiation resulted in a reversibly trans-cis isomerization reaction. The utilized radiation wavelength for isomerization depends on the chemical structure of azo-dyes. The applied radiation wavelength result in rotation outof-the $\mathrm{C}-\mathrm{N}=\mathrm{N}-\mathrm{C}$ plane occurs to change the geometry of the compounds from planar (trans-isomer) to a nonplanar, where the plane of one of the benzene rings is tilted by $56^{\circ}$ from the plane of the second ring (cis-isomer) - Figure 1 [1]. Trans-cis transformation changes a distance between the 4 and $4^{\prime}$ carbon atoms, from 9.9 to $5.5 \AA$, and resulted in the large increase a dipole moment from 0.5 to $3.1 \mathrm{D}$, respectively, for trans and cis isomers [2]. The trans-isomer is generally a more stable one (energy gap $\approx 50 \mathrm{~kJ} / \mathrm{mol}$ ) than cis-form. Azobenzenes exhibit an intense $\pi-\pi^{*}$ band at a shorter wavelength and a weak $n-\pi^{*}$ band in low energy region (Figure 1). The photo-switching properties of azobenzene derivatives are dependent on the substituents at the phenyl rings. Their modification causes a change in the position of energy states $n-\pi^{*}$ and $\pi-\pi^{*}$ bands. The improvement of the photoswitches properties can be realized by red-shift of the $\pi-\pi^{*}$ band of trans or cis isomers or by enhancing the thermal stability of the trans-form by increasing the 
energy of the $n-\pi^{*}$ transitions and lowering the energy of the $n$ orbital $[3,4]$.

Advanced amorphous azopolymers are a wide group of materials containing $-\mathrm{N}=\mathrm{N}$ - moieties between aromatic rings. One of the most important classes of amorphous polymers are polyimides containing both phenyl rings and heterocyclic imide groups $[5,6]$. This class of polymers exhibits properties interesting from their potential application in electronic, photonic, and optoelectronic applications, i.e., low dielectric constant, high heat and mechanical resistance, low susceptibility to laser light damage, and easy processability and integration in devices [7-10]. Due to the perfect combination of physicochemical properties, polyimides can be used in extreme conditions, including, e.g., separators in high power lithium batteries and microelectronic applications [11, 12].

Irradiation of azopolymer layers by polarized light can generate dichroism, photoinduced birefringence, or diffraction gratings with macroscopic mass migration resulting in the formation of sinusoidal deformation called surface relief gratings (SRG) [13]. These light-induced effects arise from selective absorption and repeated trans-cis and cis-trans isomerizations of azobenzene moieties. The decades of investigations of azopolymers gave a huge knowledge about the influence of their chemical structure on photoinduced properties. It allows for the designing of azomaterials for different applications. Within the last ten years (since 2011), amorphous azopolymers (in particular, polyimides) were intensively tested as advanced photosensitive materials in the photomechanical investigations [14-18]. The photomechanical effect is observed as bending of the free-standing films under the polarized light irradiation. This phenomenon is well-known for liquid crystalline (LC) materials and elastomers [19], but it has not been investigated in detail for glassy polymers. Bending of the azopolyimide films under the light irradiation allows applying this kind of azomaterials in new intelligent devices. The magnitude of bending angle depends on cantilever dimensions, irradiation conditions, i.e., intensity of the laser beam, kind of light polarization (perpendicular or parallel to the long axis of the cantilever), and properties of the polymer material resulting mainly from the rigidity of the polymer backbone and the content of azochromophore [20].

The photomechanical effect in azomaterials is generally investigated in liquid crystal elastomers (LCE) [21-24], liquid crystals gels [25], crosslinked liquid crystal polymers [26, 27], liquid crystal polymers $[28,29]$, and liquid crystal polymer networks [3032]. This kind of material exhibits large and fast movement of the cantilevers and low stability after turning off the excitation light. It allows the utilization of such polymers in different applications, where the high sensitivity, large mechanical response to light, and fast unbending are necessary [33-36]. Amorphous azopolymers, however, exhibit a little different photo-response. In general, glassy polymer cantilevers show lower bending angles than elastomers, but the deformation can be unchanged even after a couple of months in the dark [37]. For the first time, the photomechanical effect in amorphous azopolymers was studied by Eisenbach in 1980 [38]. Crosslinking azobenzene-containing poly(ethyl acetate) networks showed repeated construction-expansion cycles with low strain up to $0.25 \%$. In the period of the last ten years, the photomechanical effect has been studied in various amorphous materials, i.e., polyamides [39, 40], polyimides [14-17, 18, 34-44], polypeptide monolayers [45], poly(amide acid) gels [46], and trivalent crosslink polyimide [41]. Among them, the dominant position is taken by azopolyimides, that have been intensively studied by Air Force Research Laboratory (AFRL) team since 2011 $[14,16,18,20,41-43]$ and also by our research group [37, 47].

This mini-review is focused on the photomechanical effect in amorphous azobenzene-functionalized polyimides and shows the effects of $\mathrm{H}$-bonding and matrix structure are extended to azobenzene-functionalized polyamides and polystyrenes. Based on published papers, we selected the elements of the chemical structure responsible for the large bending angle of the cantilevers and its long-term stability after turning off the excitation light.

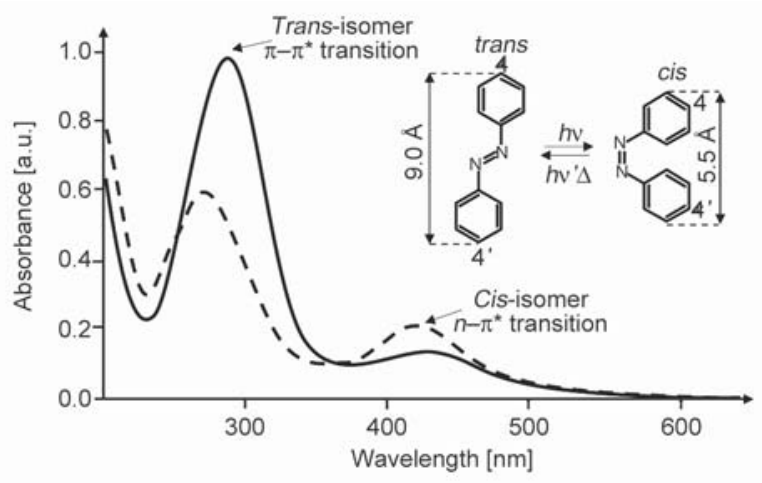

Figure 1. Trans-cis isomerization reaction and changes in the absorption spectra of trans- and cis-isomer. 


\section{The photomechanical effect}

The photomechanical effect can be manifested by the bending of a thin polymer foil $(\sim 10-30 \mu \mathrm{m})$ caused by the laser light irradiation. The mechanism of the response of polymeric material to light is associated with the trans-cis isomerization of azochromophore, reorientation of azobenzene molecules, and migration of the polymer chain during the irradiation by the excitation beam $[37,48]$.

Directing on the long axis of the polymer sample, lights with parallel polarization in the material absorption range causes perpendicular reorientation of the azochromophores. As a result, the sample shrinks along the axis and bends towards the radiation source. The opposite effect is observed when the beam is perpendicular polarized to the long axis of the sample. Then, parallel oriented azochromophores cause the sample to extend along the axis and deflect in the opposite direction to the light source (Figure 2) [18, $20,41]$. The bending of the amorphous cantilevers is the result of some optical and geometrical changes in azobenzene structure during the light irradiation, but the gradient of the absorption coefficient plays an important role. It's natural that the two sides of the cantilever absorb the light differently. The directly irradiated part of the sample absorbs much more light than the opposite (non-irradiated) side. As a result, the volume contraction is generated only in the strongly absorbed surface cantilever. Cause of that, the bending angle (defined as the angle between the line passing through the mounting and tip points and vertical direction) strongly depends on sample geometry (width and thickness) $[18,35]$. Lee and White [32] showed that photothermal effects can also occur in the liquid crystal (LC) cantilevers when the intensity of the excitation beam is above $110 \mathrm{~mW} / \mathrm{cm}^{2}$. Higher intensity of the beam can increase the local temperature of the sample and increase the efficiency of the photomechanical effect in LC foils. There is no information about the relations between the intensity of the beam and photothermal effects in high thermal stable amorphous azopolyimides. The return of the film to its initial state can occur in three different ways. Unbending can takes place spontaneously due to the thermal relaxation (Figure 2a); depending on the material, it can take from several minutes to even a couple of years; under laser irradiation with different wavelength (Figure $2 b$ ) or different polarization (Figure 2c) [37, 43, 47]. Unbending under the excitation laser is much faster than spontaneous relaxation, which can take from a second to a few minutes $[47,49,50]$. The bending angle depends on different factors such as exposure conditions (light intensity and wavelength, type of light polarization), properties of the polymer materials (concentration of azobenzene molecules, polymer network morphology, thermal and mechanical properties) [16, 20, 41, 51], and dimensions of the samples [20].

\section{Kinds of azopolymers}

Depending on the method of introducing the azochromophore into the polymer structure, azomaterials

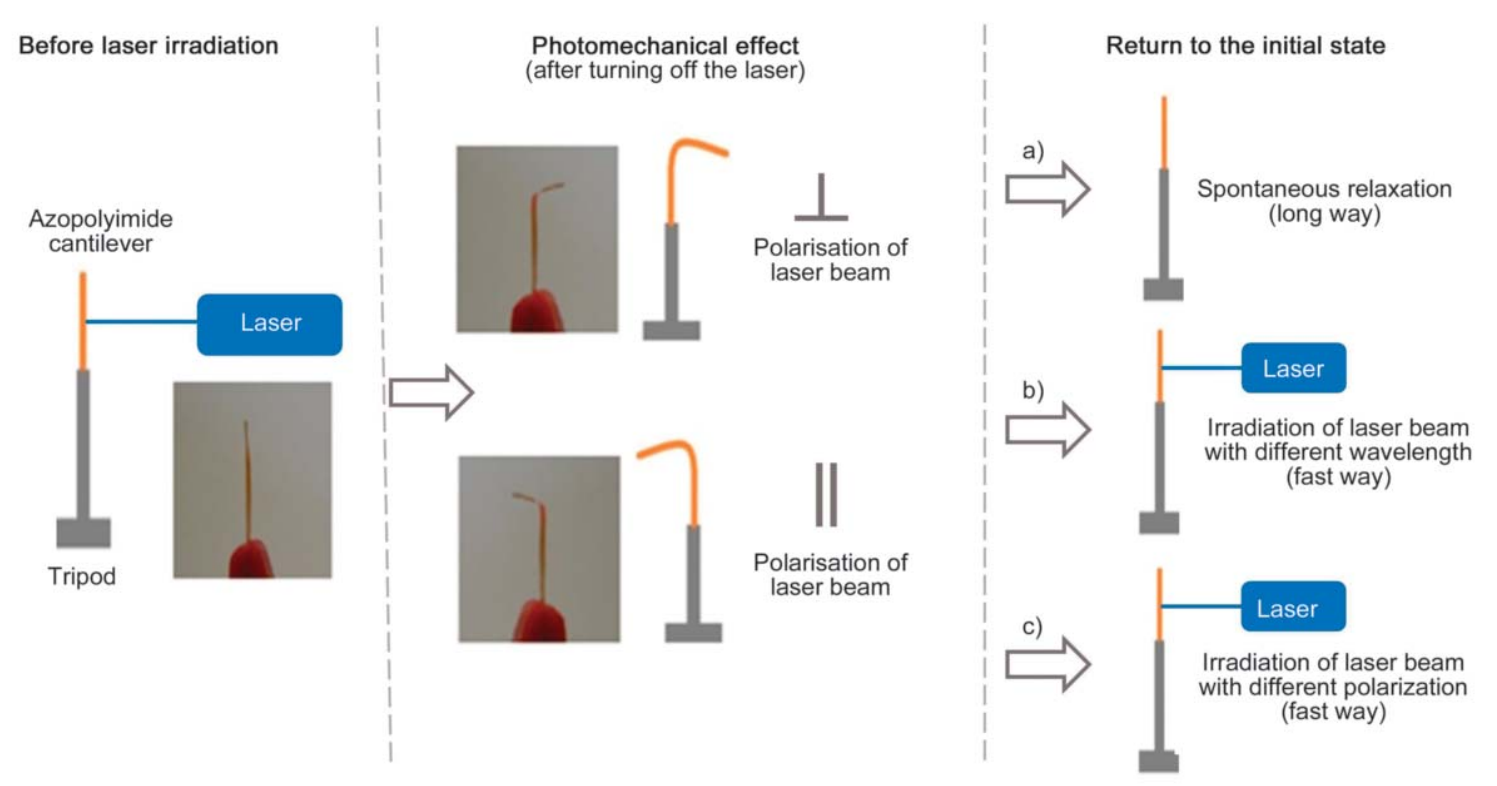

Figure 2. The photomechanical effect in stages. 
can be classified as functionalized polymers, where azomoieties are covalently bonded to the polymer backbone or 'guest-host' azo-systems with non-covalently bonded azo-dyes (Figure 3) [52]. 'Guesthost' azo-systems can be divided into two groups were the azochromophore is (i) molecularly dispersed in a polymer matrix (doped azopolymers) or (ii) connected to the polymer matrix by various noncovalent intermolecular interactions, i.e. coordination, ionic, hydrogen or by $\pi-\pi$-type interactions (supramolecular azo-systems) [13, 53, 54]. The azochromophore in functionalized polymers can be (i) an integral part of the main chain - main-chain polymers, (ii) attached as elements in the side-chain by appropriate functional group (e.g. carboxyl, hydroxyl) - side-chain polymers, or (iii) an element of both main and side-chain, where one of the aromatic rings is introduced to the main core of the polymer ('T-type' polymers) [52, 54].

Regardless of the method of attaching the azochromophore to the polymer backbone, each type of azopolymer has some advantages and disadvantages. The undoubted advantage of 'guest-host' azo-systems in comparison to functionalized polymers is the simple and cheap method of preparation, where the content of azocompounds can be easily controlled in the system [55]. However, due to the lack of a covalent bond, azochromophore molecules can sublimate or evaporate from the polymer matrix, aggregate, exhibit limited solubility in organic solvents, lowered glass transition temperature in comparison to the polymer matrix, and can result in the phase separation of the chromophore and polymer matrix [5659]. Polymers with covalently attached chromophores are free from the disadvantages of 'guest-host' azosystems. Also, the presence of a covalent bond between the azochromophore and the polymer backbone improves thermal stability compared to the 'guest-hosts' [60, 61]. However, the synthesis of functionalized polymers is much longer and hightemperature reaction conditions are used, resulting in the damage of azobenzene moieties [62].

\section{The photomechanical effect in amorphous polymers}

Amorphous azopolyimides have been studied mainly for applications in photonics and optoelectronics technologies as materials for high-density optical data storage, optical waveguides, diffractive elements, and liquid crystal alignment [57, 63-67]. In recent years, amorphous azobenzene-functionalized polyimides have been used as advanced photosensitive materials in photomechanical studies, which open new possibilities for their applications.

For the easier interpretation of the results discussed in the paper a summary table (Table 1) with

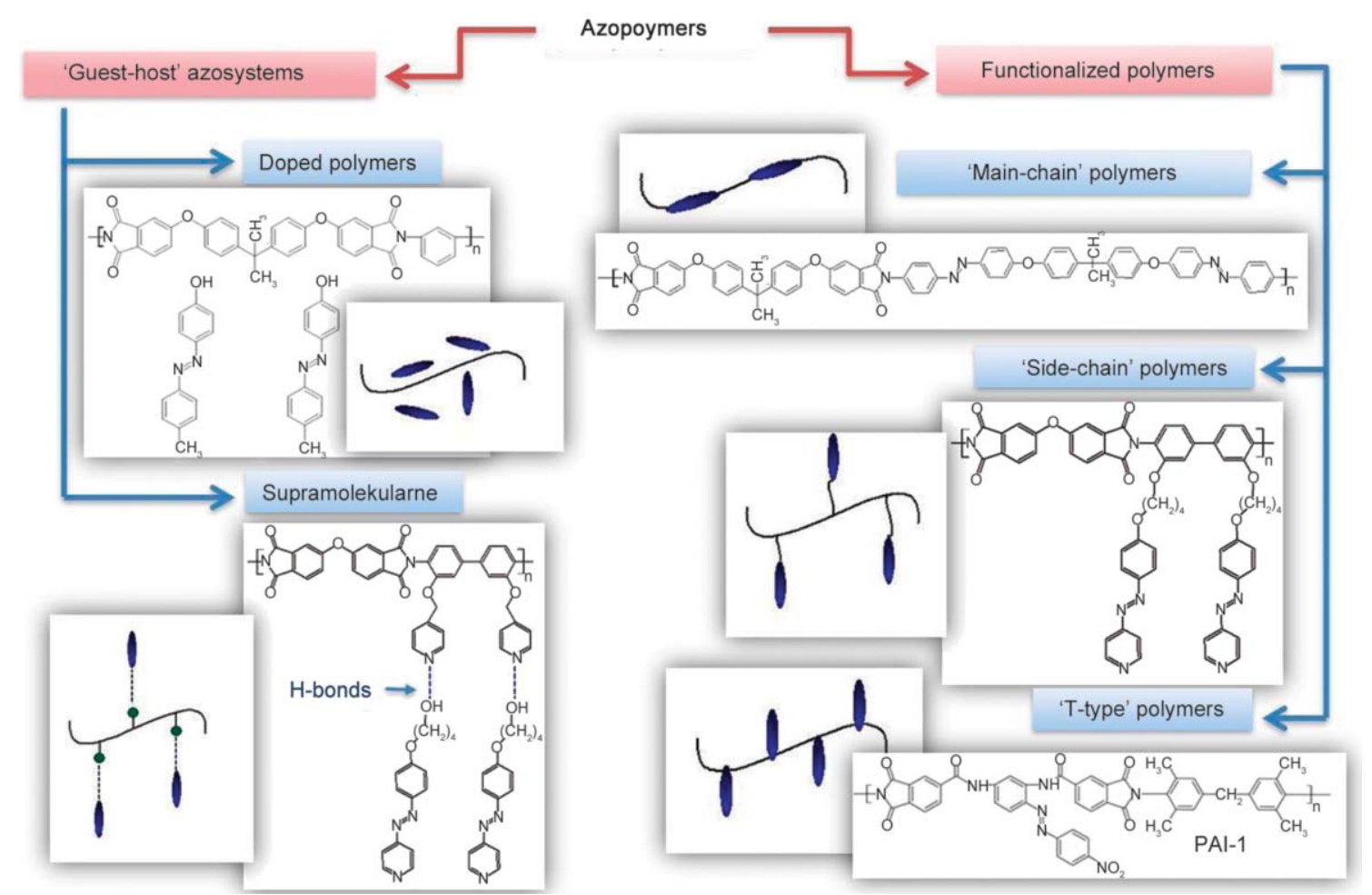

Figure 3. Different kinds of functionalized and 'guest-host' azopolymers. 
the dimensions of the cantilevers, the wavelength and intensity of the light, the polarization of the excitation beam, exposure time, bending angles, and stability of bent structures was added at the end of Chapter 4.

It can be noticed, that at the beginning, the photomechanical effect was studied only in amorphous polyimides containing azobenzene moieties in the polymer backbone. In 2012 Lee et al. [18] showed that azopolyimide free-standing films could be bending under the UV laser irradiation. The photomechanical effect was generated in linear amorphous (PI-1, PI-3) and semi-crystalline polyimides (PI-2) (Figure 4). Investigated polymers have been synthesized from 4-4'-diaminoazobenzene and flexible dianhydride 1,1,1,3,3,3-hexafluoro-2,2-bis(4-phthalic anhydride) propane (6FDA) and/or rigid pyromellitic dianhydride (PMDA). An amorphous cantilever prepared from polyimide (PI-1) $(5 \mathrm{~mm}$ (length) $\times$ $0.5 \mathrm{~mm}$ (width) $\times 0.02 \mathrm{~mm}$ (thickness)) exposed to a blue light $\left(\lambda=442 \mathrm{~nm}, I=100 \mathrm{~mW} / \mathrm{cm}^{2}\right)$ with parallel polarization $(\mathrm{E} / \mathrm{x})$ exhibited $26^{\circ}$ bending towards the light source during $60 \mathrm{~min}$ of exposure. The use of the light with perpendicular polarization $(\mathrm{E} \perp \mathrm{x})$ caused the bending of the foil by $15^{\circ}$ in the opposite direction. Increasing the width of the PI-1 cantilever from 0.5 to $1 \mathrm{~mm}$ increased the photomechanical response from 26 to $68^{\circ}$. After switching off the excitation beam, the cantilevers slowly returned to their original positions (after 3 days of relaxation, the bending angle was 14 and $9^{\circ}$ for $\mathrm{E} / / \mathrm{x}$ and $\mathrm{E} \perp \mathrm{x}$, respectively). The photomechanical effect was not observed for semi-crystalline $\mathbf{P I - 2}$ polyimide under the same exposure conditions. A strong effect of crystallinity on photomechanical response was observed. Cantilevers prepared from co-polyimide PI-3 (5 mm (length) $\times 1 \mathrm{~mm}$ (width) $\times 0.02 \mathrm{~mm}$ (thickness) were characterized a different degree of crystallinity
$(12.5,25,37.5 \%)$. Irradiation with a parallel polarized light caused a decrease in the bending angle with an increase in the degree of crystallinity, which is the result of hindering the isomerization of the azochromophores by the stiffness of the crystal areas. The bending angles for the co-polyimides with 12.5 , 25 , and $37.5 \%$ crystallinity were ca. 65,20 , and $7^{\circ}$, respectively.

Shankar et al. [17] describes the rapid response of amorphous polyimide under the low intensity light $\left(\lambda=445 \mathrm{~nm}, I=18 \mathrm{~mW} / \mathrm{cm}^{2}, E / / \mathrm{x}\right)$. Studied co-polyimide PI-4a was prepared from 6FDA dianhydride, 1,3-bis(3-aminophenoxy) benzene (APB) and 2,2-bis \{4-[4-(4-aminophenyldiazenyl)phenoxy]phenyl\}propane (azo-BPA) (45\% azo-BPA: 55\% APB) (Figure 5). The polyimide foil (20 mm (length) $\times 1 \mathrm{~mm}$ (width) $\times 15 \mu \mathrm{m}$ (thickness)) was clamped at both ends and bent into a small arch, forming a concave structure. Then, the foil was irradiated in the center (the convex side facing the laser) using blue laser light. As a result, the sample succumbed quickly $\left(t_{\text {irradiation }}=\right.$ $8.4 \mathrm{~s}$, stroke length $\sim 1 \mathrm{~mm}$, stroke speed $\sim 100 \mathrm{~mm} / \mathrm{s}$ ) to the photogenerated deformation in the opposite direction, thereby forming a convex structure.

The influence of azobenzene units' concentration in co-polyimide structures on the photomechanical response was discussed in the paper [15]. The content of azomoieties in PI-4a structure was 30, 35, 45, 70, or $100 \mathrm{~mol} \%$ (Figure 5). Prepared cantilevers (6 mm (length) $\times 0.1 \mathrm{~mm}$ (width) $\times 0.02 \mathrm{~mm}$ (thickness) were irradiated with linearly polarized light $(\lambda=$ $\left.445 \mathrm{~nm}, I=120 \mathrm{~mW} / \mathrm{cm}^{2}, \mathrm{E} / / \mathrm{x}, t=1 \mathrm{~h}\right)$. The bending angle was dependent on the concentration of azoBPA monomer, which grew up from 19 to $80^{\circ}$ for 30 and $100 \%$ of azo-BPA content, respectively. The complete relaxation to the initial state of the samples with 70 and $100 \mathrm{~mol} \%$ azo-BPA was observed, while the copolymer with $30 \%$ of azo-BPA content retains
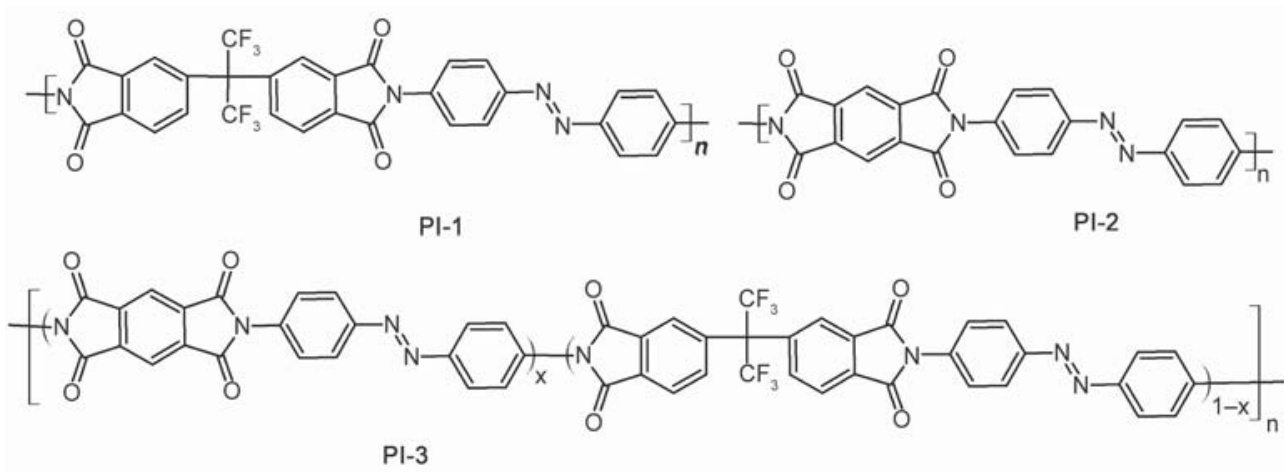

Figure 4. Chemical structures of homo- (PI-1, PI-2) and co-polyimides (PI-3) with 4-4'-diaminoazobenzene moieties [18]. 


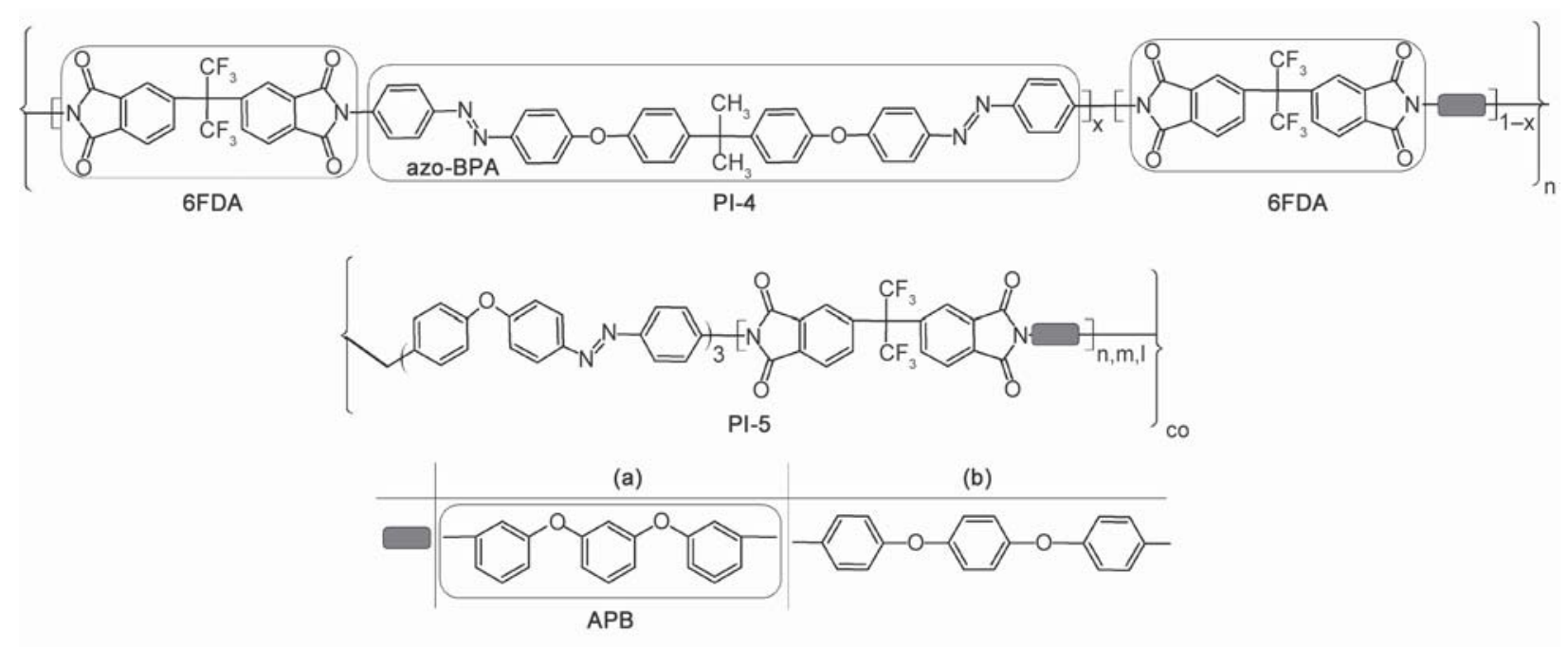

Figure 5. Chemical structures of co-polyimides PI-4a,b and PI-5a,b [14, 15, 17].

a deformation of $14^{\circ}$, after 10 days of dark return. This may be due to the difference in the storage modulus of polymers (1.74 vs $1.10 \mathrm{GPa}$ for 100 and $30 \%$ content of azo-BPA, respectively). Higher content of azomoieties increased the flexibility of the polymer backbone and decreased the stability of the bent. A similar impact of the rigidity of the polymer backbone on the shape stability was observed in work [43].

Skandani et al. [68] investigated repetitive bending and the number of recovery cycles for azopolyimide PI-5a. The two ends of the photoreactive material (14 mm (length) $\times 1 \mathrm{~mm}$ (width) $\times 15 \mu \mathrm{m}$ (thickness) were clamped between the aluminum plates, which formed a bent, bistable arc of the azopolymer foil. The azopolyimide arc could be bent up or down, i.e., be in one of two stable states that do not require external power. The polyimide film was irradiated with a laser from above $\left(\lambda=375 \mathrm{~nm}, \mathrm{E} / \mathrm{x}, I=25 \mathrm{~mW} / \mathrm{cm}^{2}\right.$, laser beam diameter $5 \mathrm{~mm}$ falling on the center of the arc) causing quickly reverse the arc in the opposite direction $\left(t=\sim 94 \mathrm{~s}\right.$ for $\left.I=0.2 \mathrm{~mW} / \mathrm{cm}^{2}\right)$. Then exposure of the film to laser irradiation with a wavelength of $445 \mathrm{~nm}\left(I=25 \mathrm{~mW} / \mathrm{cm}^{2}, t=300 \mathrm{~s}\right)$ regenerated the trans-isomers, ensuring repeated toggling of an actuator between stable states. The first film toggling was the slowest, while the subsequent toggling cycles came faster for the next 25 toggling cycles. In work [14] the impact of the segmental mobility on the photomechanical effect in linear and crosslinked amorphous polyimides containing azobenzene groups in the main chain was analyzed. For this purpose, polyimides contained aminophenoxybenzene (APB) parts with phenyl rings attached in the meta (PI-4a) and para position (PI-4b), as well as its analogous (PI-5a) and (PI-5b), were obtained
(Figure 5). It was found that the kind of phenyl ring substitution (meta or para) strongly affects the photomechanical response. During irradiation of azopolymer foils $(6 \mathrm{~mm}$ (length) $\times 0.1 \mathrm{~mm}$ (width) $\times 0.02 \mathrm{~mm}$ (thickness)) with a blue light $(\lambda=445 \mathrm{~nm}, I=$ $\left.120 \mathrm{~mW} / \mathrm{cm}^{2}, \mathrm{E} / / \mathrm{x}, t=1 \mathrm{~h}\right)$, a larger photomechanical bending for para (ca. 50 and $67^{\circ}$ for PI-4b and PI-5b, respectively) than meta substitution (ca. 23 and $24^{\circ}$ for PI-4a and PI-5a, respectively) was observed. The difference in relaxation was also seen when the samples were left for 3 days in the dark. The bending of the cantilevers prepared from polyimides with para-substituted phenyl rings was more stable (retaining bent $68 \%$ for PI-4b and $82 \%$ for PI-5b) in comparison to the meta analogues ( $9 \%$ and $62 \%$ for PI-4a and PI-5a, respectively). It can be the result of increased mobility of the segments due to the greater freedom of rotation of the phenyl rings substituted in the para position.

Wang et al. [43] reported the influence rigidity of polymer backbone on the photomechanical effect in a series of polymers presented in Figure 6. Polyimides were obtained from 2,2-bis \{4-[4-(4aminophenyldiazenyl)phenoxy]phenyl $\}$-propane (azo-BPDA) (PI-6) and one of the anhydrides: PMDA (a), BPDA (b), BTDA (c), 6FDA d), OPDA (e) (Figure 6). Polyimides containing BTDA (c), 6FDA (d), as those prepared from PMDA (a) and BPDA (b) were characterized by a low degree of crystallinity ( 1.5 and $0.4 \%$ respectively). The photoinduced bending of the cantilevers $(6 \mathrm{~mm}$ (length) $\times 2 \mathrm{~mm}$ (width) $\times 0.02 \mathrm{~mm}$ (thickness)) under the blue light irradiation $\left(\lambda=445 \mathrm{~nm}, I=120 \mathrm{~mW} / \mathrm{cm}^{2}, \mathrm{E} / / \mathrm{x}, t=1 \mathrm{~h}\right)$ was weaker for polyimides prepared from dianhydrides with higher rigidity PMDA (a) and BPDA (b) (15 


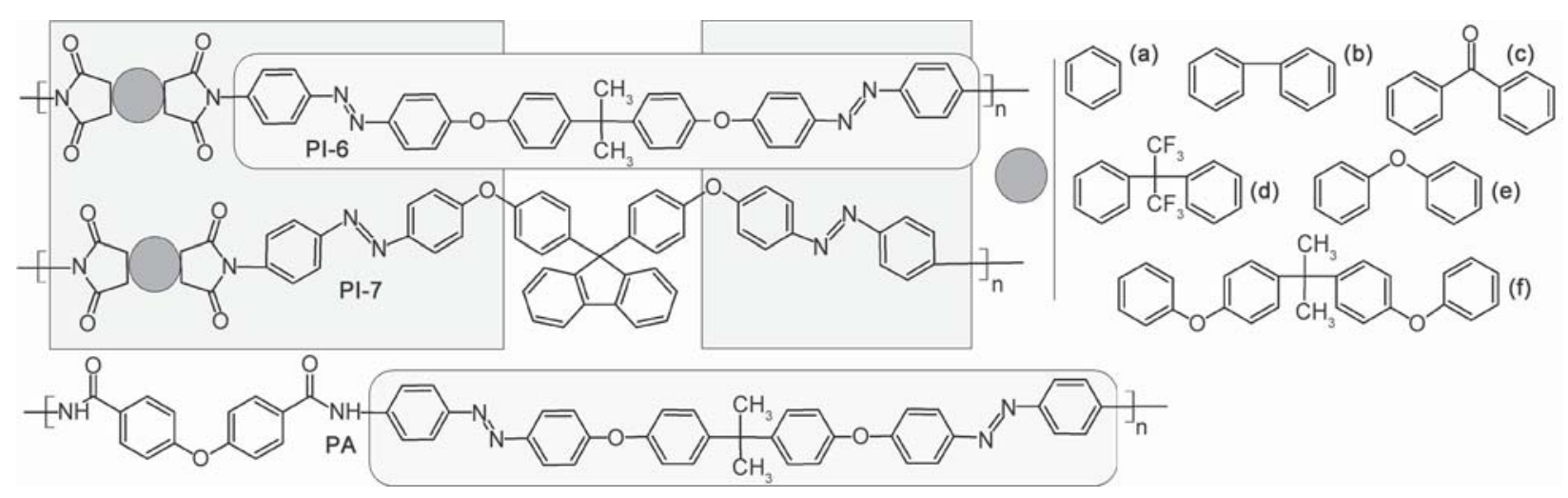

Figure 6. Chemical structures of main-chain azopolyimides PI-6(a-e), PI-7(a-f), and azopolyamide (PA) [16, 39, 43].

and $40^{\circ}$, respectively) than for more flexible counterparts BTDA (c), 6FDA (d) and OPDA (e) $(55,85$, and $90^{\circ}$, respectively). Besides, polyimide PI-6e with the most flexible segments regained its original shape after about 1 hour of dark return, while the most rigid polymer (PI-6a) needed 10 days to recover the initial state. This may be due to smaller free volume in rigid polyimides that inhibit the trans-cistrans azobenzene isomerization.

White and co-workers [16] investigated amorphous polyimides (PI-7(a-f)) similar in the structure to polymers denoted as PI-6(a-e) (Figure 6). Irradiation of polyimide cantilevers $(6 \mathrm{~mm}$ (length) $\times 1 \mathrm{~mm}$ (width) $\times 0.02 \mathrm{~mm}$ (thickness)) with low intensity blue laser beam $\left(\lambda=445 \mathrm{~nm}, I=60 \mathrm{~mW} / \mathrm{cm}^{2}, \mathrm{E} / / \mathrm{x}\right.$, $t=30 \mathrm{~min}$ ) resulted in bending of all-polymer foils. The maximum bending angles were in the range of $\sim 45-70^{\circ}$, where the influence of the rigidity of the anhydride part was not observed. After turning off the excitation laser, the full recovery to the initial state was observed by 2 hours, where ca. $70 \%$ of unbending occurred within $30 \mathrm{~min}$. Large deformation and relatively fast unbending of the free-standing films prepared from polyimides PI-7 can be a result of an increase in local free volume by incorporation 'cardo-group' that enhances the mobility of azobenzene moieties.

The impact of the inter-chain hydrogen bonds on the photomechanical response was presented in ref. [39]. Two amorphous polymers, i.e., azopolyamides (PAs) that are capable of forming the intermolecular hydrogen bonds, and azopolyimide PI-6e (Figure 6) that do not have such capability, were investigated. Prepared cantilevers $(6 \mathrm{~mm}$ (length) $\times 0.1 \mathrm{~mm}$ (width) $\times 0.02 \mathrm{~mm}$ (thickness)) exposed to the blue light $(\lambda=$ $445 \mathrm{~nm}, I=120 \mathrm{~mW} / \mathrm{cm}^{2}, t=1 \mathrm{~h}$ ) showed the bending angles of 78 and $85^{\circ}$ for PA and PI-6e, respectively. The presence of the intermolecular interactions did not affect the photo-deformation of the polymer films. During the laser irradiation, the intermolecular H-bonds were destroyed, and the rigidity of PA chains was reduced. After turning off the excitation laser, the relaxation of the cantilevers to the initial position was slower for azopolyamide due to the reformation of the hydrogen bonds, which slow down the unbending process.

To the best of our knowledge, for the first time, the photomechanical effect in polyimides containing azochromophore attached in the side chain of the polymer backbone was reported in our work [47]. The investigated poly(amide imide)s were synthesized from dianhydride with azobenzene unit substituted in the para position with a nitro group, and four different diamines (PI-8(a-d)). Chemical structures of 'T-type' azopolyimides are shown in Figure 7. The maximum deformations of polymer samples $(5 \mathrm{~mm}$ (length) $\times$ ca. $1.2 \mathrm{~mm}$ (width) $\times 4-7 \mu \mathrm{m}$ (thickness)) were generated within $1-2 \mathrm{~min}$ of laser irradiation $(\lambda=$ $\left.445 \mathrm{~nm}, I=80 \mathrm{~mW} / \mathrm{cm}^{2}, \mathrm{E} / / \mathrm{x}\right)$. The bending angles were $60,70,55$, or $40^{\circ}$ for PI-8(a-d), respectively. It is seen that the more flexible backbone of the polymers PI-8(a-c) increased the bending angle. The unbending was not observed during 10 days after turning off the excitation laser. Long-term stability of the bending can be a result of the formation of the intermolecular hydrogen bonds between amide groups and/or incorporation azobenzene moieties to the side chain. The cis-trans isomerization of azomoieties attached to the side-chain does not influence the polymer backbone; as a result, the bending of the cantilever is more stable. In this work, bidirectional of the cantilever, bending was shown. At the first stage, polymer samples (3-4 mm (length) $\times 0.33-0.45 \mathrm{~mm}$ (width) $\times 4-7 \mu \mathrm{m}$ (thickness)) were irradiated by polarized laser beam in a parallel direction to the long axis of the samples $\left(\lambda=445 \mathrm{~nm}, I=80 \mathrm{~mW} / \mathrm{cm}^{2}\right.$, 


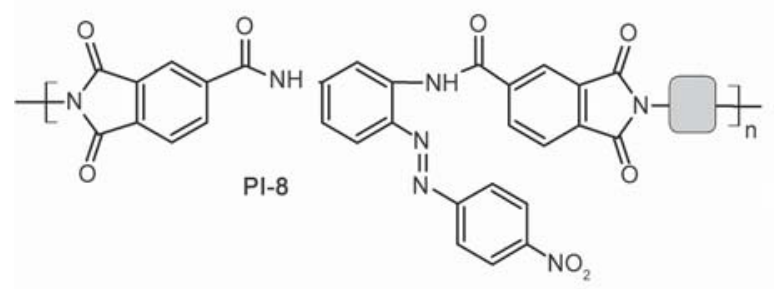

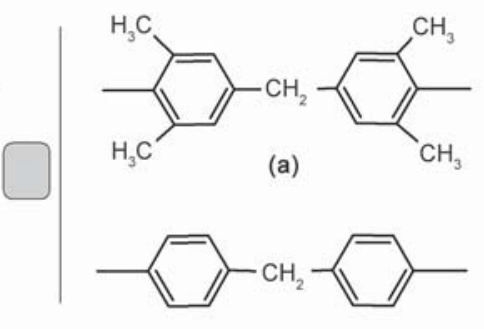

(c)

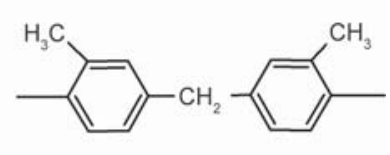

(b)

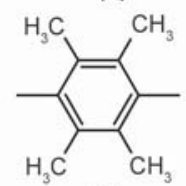

(d)

Figure 7. Chemical structures of 'T-type' azopoly(amide imide)s (PI-8(a-d)) [47].

E//x) by $45-100 \mathrm{~s}$. The bending was observed for all polyimide free-standing films. Then, the polymers were irradiated by the laser beam with perpendicular polarization for ca. 1-2 min. It was shown that reverse motions were not symmetrical. For all polyimides, bending towards the laser source was significantly more efficient than in the reverse direction. The photomechanical effect was also generated in amorphous polymers, where azo-dyes are not covalently attached to the polymer chain [37]. A series of 'guest-host' systems were prepared from matrices: polystyrene (PS) or poly(ether imide) (PI-9) doped with two types of dyes 4-[(4-methyl phenyl)diazenyl] phenol (Az-1) or 4-[4-(6-hydroxyhexyloxy)phenylazo]methylbenzene (Az-2) with 10 or $50 \mathrm{wt} \%$ chromophore concentration (Figure 8). Polymer matrices and azopolymer cantilevers $(8 \mathrm{~mm}$ (length) $\times 2 \mathrm{~mm}$ (width) $\times$ ca. $30 \mu \mathrm{m}$ (thickness)) were exposed to the excitation beam $\left(\lambda=405 \mathrm{~nm}, I=150 \mathrm{~mW} / \mathrm{cm}^{2}, \mathrm{E} / / \mathrm{x}\right.$, $t=15 \mathrm{~s}-5 \mathrm{~min})$. The bending was not observed for polymer matrices that would confirm that the photodeformation is the result of the isomerization of azobenzene moieties. The photomechanical effect was observed for almost all 'guest-host' azo-systems, where the impact of different factors on the maximum bending angle was observed. The higher bending angle of free-standing films was detected for polymers prepared from polystyrene than polyimide matrices, probably due to the more flexible polymer backbone of polystyrene. Better photoresponse properties were observed for materials contain azochromophore with a hydroxyl group that can be connected to faster trans-cis conversion of Az-1. Our previous studies showed that the photoisomerization reaction is faster and more efficient for azo-dyes with hydroxyl groups than for chromophores with a long<smiles>CCCc1ccccc1</smiles>

(PS)

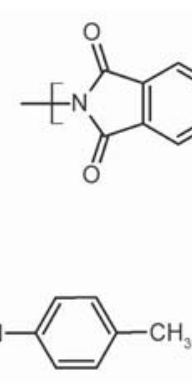

(Az-1)<smiles>Cc1cccc(N2C(=O)c3ccc(Oc4ccc(C(C)(C)C)cc4)cc3C2=O)c1</smiles>

(PI-9)

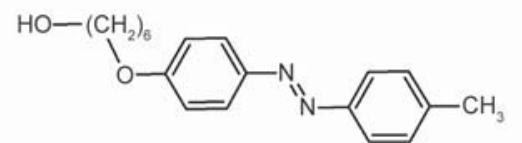

\begin{tabular}{|c|c|c|}
\hline $\begin{array}{c}\text { Polymer } \\
\text { matrix }\end{array}$ & $\begin{array}{c}\text { Azo } \\
\text { dye }\end{array}$ & $\begin{array}{c}{[w+\%]} \\
\text { azo dye }\end{array}$ \\
\hline \multirow{3}{*}{ PS } & \multirow{2}{*}{ Az-1 } & 10 \\
\cline { 2 - 3 } & \multirow{2}{*}{ Az-2 } & 50 \\
\cline { 2 - 3 } & & 10 \\
\hline \multirow{3}{*}{ PI-9 } & Az-1 & 10 \\
\cline { 2 - 3 } & \multirow{2}{*}{ Az-2 } & 50 \\
\cline { 3 - 3 } & & 10 \\
\hline
\end{tabular}
(Az-2)

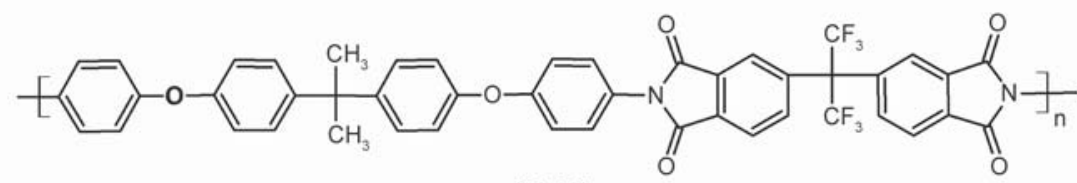

(PI-10)

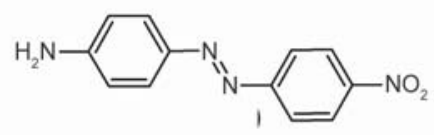

$(\mathrm{Az}-3)$

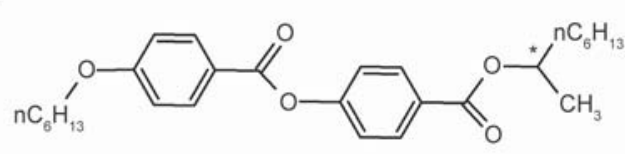

(PART)

Figure 8. Chemical structures of 'guest-host' azopolymers: polystyrene (PS) and polyimide (PI-9) matrices mixed with azochromophores Az-1 or Az-2. Polyimide PI-10 is mixed with Az-3 and/or left-handed chiral particles (PART) [37, 48]. 
aliphatic chain [69]. The higher content of azochro-

to $120^{\circ}$ for polystyrene with $50 \mathrm{wt} \%$ of 4 -[(4-methyl mophore increased the bending angle of the films up

phenyl)diazenyl]phenol (PS[Az-1]). No relaxation of

Table 1. Experimental conditions, values of bending angles, and unbending time for amorphous azopolymer cantilevers.

\begin{tabular}{|c|c|c|c|c|c|c|}
\hline Polymer code & $\begin{array}{l}\text { Dimensions of } \\
\text { cantilever }\end{array}$ & $\begin{array}{l}\text { Conditions of } \\
\text { irradiation }\end{array}$ & \multicolumn{2}{|c|}{ Photomechanical effect } & \multicolumn{2}{|c|}{ Relaxation } \\
\hline & \multirow{2}{*}{$\begin{array}{c}\text { length }[\mathrm{mm}] \times \\
\text { width }[\mathrm{mm}] \times \\
\text { thickness }[\mu \mathrm{m}]\end{array}$} & \multirow{2}{*}{$\begin{array}{c}\lambda[\mathrm{nm}] \\
I\left[\mathrm{~mW} / \mathrm{cm}^{2}\right] \\
\text { polarization }(E / / \text { or } \perp)\end{array}$} & $\begin{array}{c}\text { Bending angle } \\
{\left[{ }^{\circ}\right]}\end{array}$ & $\begin{array}{c}\text { Time of } \\
\text { irradiation }\end{array}$ & $\begin{array}{c}\text { Bending angle } \\
{\left[{ }^{\circ}\right]}\end{array}$ & \begin{tabular}{|c|} 
Time of \\
undending
\end{tabular} \\
\hline & & & \multicolumn{2}{|c|}{ other observations } & \multicolumn{2}{|c|}{ other observations } \\
\hline \multirow{2}{*}{ PI-1 } & \multirow{5}{*}{$5 \times 0.5 \times 20$} & $\begin{array}{c}\lambda=442 \\
I=100 \\
\mathrm{E} / / \mathrm{x}\end{array}$ & 26 & \multirow{5}{*}{$1 \mathrm{~h}$} & \multirow[t]{2}{*}{14} & 3 days \\
\hline & & $\begin{array}{c}\lambda=442 \\
I=100 \\
\mathrm{E} \perp \mathrm{x}\end{array}$ & 15 & & & \\
\hline $\begin{array}{c}\text { PI-3 } \\
\text { (cryst } 12.5 \% \text { ) }\end{array}$ & & \multirow{3}{*}{$\begin{array}{c}\lambda=442 \\
I=100 \\
\mathrm{E} / / \mathrm{x}\end{array}$} & 65 & & \multirow{3}{*}{\multicolumn{2}{|c|}{-}} \\
\hline $\begin{array}{c}\text { PI-3 } \\
\text { (cryst 25\%) }\end{array}$ & & & 20 & & & \\
\hline $\begin{array}{c}\text { PI-3 } \\
\text { (cryst } 37.5 \% \text { ) }\end{array}$ & & & 7 & & & \\
\hline PI-4a & $20 \times 1 \times 15$ & $\begin{array}{c}\lambda=445 \\
I=18 \\
\mathrm{E} / / \mathrm{x}\end{array}$ & $\begin{array}{c}\text { Arch bending: } \\
\text { stroke length } \sim 1 \mathrm{~mm}, \\
\text { stroke speed } \sim 100 \mathrm{~mm} / \mathrm{s}\end{array}$ & $8.4 \mathrm{~s}$ & \multicolumn{2}{|l|}{-} \\
\hline $\begin{array}{c}\text { PI-4a } \\
(30 \% \text { mol azo moieties })\end{array}$ & \multirow{6}{*}{$6 \times 0.1 \times 20$} & \multirow{11}{*}{$\begin{array}{c}\lambda=445 \\
I=120 \\
\mathrm{E} / / \mathrm{x}\end{array}$} & 19 & \multirow{11}{*}{$1 \mathrm{~h}$} & 14 & \multirow{2}{*}{10 days } \\
\hline $\begin{array}{c}\text { PI-4a } \\
(100 \% \text { mol azo moieties })\end{array}$ & & & 80 & & 0 & \\
\hline PI-4a & & & 23 & & 2 & \\
\hline PI-4b & & & 50 & & 34 & \\
\hline PI-5a & & & 24 & & 15 & 3 days \\
\hline PI-5b & & & 67 & & 55 & \\
\hline PI-6a & & & 15 & & 0 & 10 days \\
\hline PI-6b & & & 40 & & & \\
\hline PI-6c & $6 \times 2 \times 20$ & & 55 & & - & \\
\hline PI-6d & & & 85 & & & \\
\hline PI-6e & & & 90 & & 0 & $1 \mathrm{~h}$ \\
\hline PI-7a & & & 63 & & 2 & \\
\hline PI-7b & & & 68 & & 5 & \\
\hline PI-7c & $6 \times 1 \times 20$ & $\begin{array}{l}\lambda=445 \\
J=60\end{array}$ & 62 & $30 \mathrm{~min}$ & 4 & $2 \mathrm{~h}$ \\
\hline PI-7d & $0 \times 1 \times 20$ & $\mathrm{E} / / \mathrm{x}$ & 65 & Jण & 7 & 211 \\
\hline PI-7e & & & 70 & & 10 & \\
\hline PI-7f & & & 45 & & 3 & \\
\hline PA & & $\lambda=445$ & 78 & & Slower that & a PI-6e \\
\hline PI-6e & $6 \times 0.1 \times 20$ & $\begin{array}{c}I=120 \\
-\end{array}$ & 85 & $1 \mathrm{~h}$ & Faster the & an PA \\
\hline PI-8a & & & 60 & & & \\
\hline PI-8b & $5 \times 12 \times 47$ & $\begin{array}{l}\lambda=445 \\
I=80\end{array}$ & 70 & $12 \mathrm{~min}$ & Strble for & 10 dave \\
\hline PI-8c & $3 \times 1.2 \times 4-1$ & $\mathrm{E} / / \mathrm{x}$ & 55 & $1-2 \mathrm{mIm}$ & Stavie 101 & 10 days \\
\hline PI-8d & & & 40 & & & \\
\hline PS[Az-1] & $8 \times 2 \times 30$ & $\begin{array}{c}\lambda=405 \\
I=150 \\
\mathrm{E} / / \mathrm{x}\end{array}$ & 120 & $2 \mathrm{~min}$ & Stable for 6 & 6 months \\
\hline PI-10[Az-3]PART & $2.5 \times 0.8 \times 9.8$ & $\begin{aligned} \lambda & =365 \\
I & =30 \\
& -\end{aligned}$ & 3D shape-persistent elas & stic helixes & $\begin{array}{l}\text { Kept the elastic } \\
1000 \text { stretching-r } \\
\text { cles and heating }\end{array}$ & $\begin{array}{l}\text { c form after } \\
\text { relaxation cy- } \\
\text { up to } 100^{\circ} \mathrm{C}\end{array}$ \\
\hline
\end{tabular}


the bending was observed after 6 months after turning off the excitation laser for all 'guest-host'azopolymers. In this work, a mechanism of the photomechanical effect in glassy azopolymers was proposed. It was shown, that bending of the cantilevers may be associated with an increase in the population of cis-isomers, reorientation of the trans-azo molecules, and migration of the polymer chain under the laser beam irradiation. It should be noticed that at the same time, Li et al. [48] come to the same conclusions. They investigated 'guest-host' systems based on a polyimide matrix (PI-10) doped with 4-(4-nitrophenylazo)aniline (Az-3) (the molar ratio 1 (PI-10): 23.7 (Az-3)) with the addition of right or left-handed chiral particles (PART) (Figure 8). Prepared samples $(2.5 \mathrm{~mm}$ (length) $\times 0.8 \mathrm{~mm}$ (width) $\times$ $9.8 \mu \mathrm{m}$ (thickness)) were exposed to LPUV light to generate a molecular alignment of the polymer chains. Irradiation with the UV-light $(\lambda=365 \mathrm{~nm}, I=$ $30 \mathrm{~mW} / \mathrm{cm}^{2}$ ) resulted in fabrication 3D shape-persistent elastic helixes. The prepared azo-systems kept the elastic form after 1000 stretching-relaxation cycles and heating up to $100^{\circ} \mathrm{C}$.

\section{Conclusions}

The work aims to summarize the information about the photomechanical effect of amorphous azobenzene-functionalized polymers include the mechanism of the cantilever bending under the laser irradiation, the potential application of the effect, and the relationship between chemical structure and response of the cantilevers. Based on the results presented in this short review, the effect of the individual elements of the polymer chemical structure on the photomechanical response and its stability after turning off the excitation laser was showed below:

- kind of attachment of azochromophores - azobenzene moieties covalently incorporated into the polymer structure or dispersed molecularly in the polymer matrix ('guest-host' system). Considering the time needed to reach the maximum cantilever deflection, the fastest mechanical response exhibit 'guest-host' azopolymers (a dozen of seconds - a few minutes), while functionalized polymers with azo-units in the main chain need a longer time even tens of minutes. 'Guest-host' azo-systems exhibit much greater stability of the cantilever bending than covalently bonded polymers. The unbending is not observed at least 6 months after turning off the excitation light, while the time needed to unbending for main- and the side-chain polymer is (in general) from a $1 \mathrm{~h}$ to several days. The excellent bending stability of 'guest-host' azopolymers foils can be a result of the non-covalent attachment of azomolecules to the polymer backbone,

- the content of azobenzene moieties - increase the azomoieties content (in both functionalized and 'guest-host' azopolymers) increases the photoresponse of free-standing films, but does not influence on the stability of the bending after turning off the laser,

- degree of the crystallinity - increase the degree of the crystalline phase results in hindering the isomerization of azochromophores by the stiffness of the crystal areas and in the result, the bending angles are lower than for fully amorphous analogues. The crystalline phase decreases the free volume necessary for trans-cis isomerization of azocompounds. However, a low degree of crystalline phase can stabilize the bending angles after turning off the laser,

- rigidity/flexibility of the polymer backbone - polymers with a more flexible backbone (realized by introducing of ether, ester, $\mathrm{CF}_{3}$, or aliphatic groups) exhibit faster and larger photoresponse than polymers with a more rigid structure. Considering the bending stability, a more rigid structure improved the photoinduced shape fixity compared to polymers with a flexible backbone,

- intermolecular H-bonds - the presence of the intermolecular hydrogen bonds does not affect increasing the bending angles of the cantilevers. As a result of the fast trans-cis isomerization of the azomoieties generated by the laser beam, the hydrogen bonds are broken. The intermolecular H-bonds affect the large stability of the bending. After turning off the excitation light, the $\mathrm{H}$-bonds are rebuilt. The non-covalent connection between polymer chains stiffens the structure, and thermal/spontaneous cis-trans isomerization and reorientation of azobenzene molecules are less efficient.

Our mini-review shows that azopolyimides are promising materials for applications where the high deformation stability of free-standing films is necessary. The stability of the shape of the amorphous cantilever can be stable even 6 months after turning off the excitation light for 'guest-host' polymers. We showed that side-chain azopolyimides were not studied in the context of the photomechanical effect, except these polymers investigated by our research group. It was 
found that this kind of polymers can exhibit fast bending with higher photoinduced deformation stability than main-chain polyimides. Preparation of the side-chain azopolyimide cantilevers can be a promising concept for future studies. We believe that the paper will help in design new amorphous azopolymers exhibiting the properties adapted towards specific applications.

\section{Acknowledgements}

This research was funded by the National Science Centre, Poland, grant number UMO-2019/35/D/ST5/00533.

\section{References}

[1] Hamon F., Djedaini-Pilard F., Barbot F., Len C.: Azobenzenes - Synthesis and carbohydrate applications. Tetrahedron, 65, 10105-10123 (2009). https://doi.org/10.1016/j.tet.2009.08.063

[2] Nicoletta F. P., Cupelli D., Formoso P., De Filpo G., Colella V., Gugliuzza A.: Light responsive polymer membranes: A review. Membranes, 2, 134-197 (2012). https://doi.org/10.3390/membranes2010134

[3] Samanta S., Beharry A. A., Sadovski O., McCormick T. M., Babalhavaeji A., Tropepe V., Woolley G. A.: Photoswitching azo compounds in vivo with red light. Journal of the American Chemical Society, 135, 9777-9784 (2013).

https://doi.org/10.1021/ja402220t

[4] Knie C., Utecht M., Zhao F. L., Kulla H., Kovalenko S., Brouwer A. M., Saalfrank P., Hecht S., Bleger D.: orthofluoroazobenzenes: Visible light switches with very longlived $\mathrm{Z}$ isomers. Chemistry A: European Journal, 20, 16492-16501 (2014).

https://doi.org/10.1002/chem.201404649

[5] Yesodha S. K., Pillai C. K. S., Tsutsumi N.: Stable polymeric materials for nonlinear optics: A review based on azobenzene systems. Progress in Polymer Science, 29, 45-74 (2004).

https://doi.org/10.1016/j.progpolymsci.2003.07.002

[6] Ma P., Dai C., Wang H., Li Z., Liu H., Li W., Yang C.: A review on high temperature resistant polyimide films: Heterocyclic structures and nanocomposites. Composites Communications, 16, 84-93 (2019).

https://doi.org/10.1016/j.coco.2019.08.011

[7] Sroog C. E.: Polyimides. Progress in Polymer Science, 16, 561-694 (1991). https://doi.org/10.1016/0079-6700(91)90010-I

[8] Kozanecka-Szmigiel A., Konieczkowska J., Szmigiel D., Switkowski K., Siwy M., Kuszewski P., Schab-Balcerzak E.: Photoinduced birefringence of novel azobenzene poly(esterimide)s; The effect of chromophore substituent and excitation conditions. Dyes and Pigments, 114, 151157 (2015).

https://doi.org/10.1016/j.dyepig.2014.11.007
[9] Eastmond G. C., Gibas M., Pacynko W. F., Paprotny J.: Grafted and segmented hydrophilic polyimides for microfiltration membranes: Part I. Synthesis and characterization. Journal of Membrane Science, 207, 29-41 (2002). https://doi.org/10.1016/S0376-7388(01)00750-5

[10] Lin H-L., Juang T-Y., Chan L-H., Lee R-H., Dai S. A., Liu Y-L., Su W-C., Jeng R-J.: Sequential self-repetitive reaction toward wholly aromatic polyimides with highly stable optical nonlinearity. Polymer Chemistry, 2, 685-693 (2011). https://doi.org/10.1039/C0PY00157K

[11] Jiang W., Liu Z., Kong Q., Yao J., Zhang C., Han P., Cui G.: A high temperature operating nanofibrous polyimide separator in Li-ion battery. Solid State Ionics, 232, 44-48 (2013). https://doi.org/10.1016/j.ssi.2012.11.010

[12] Hedrick J. L., Carter K. R., Cha H. J., Hawker C. J., DiPietro R. A., Labadie J. W., Miller R. D., Russell T. P., Sanchez M. I., Volksen W., Yoon D. Y., Mecerreyes D., Jerome R., McGrath J. E.: High-temperature polyimide nanofoams for microelectronic applications. Reactive and Functional Polymers, 30, 43-53 (1996).

https://doi.org/10.1016/1381-5148(96)00020-X

[13] Vapaavuori J., Bazuin C. G., Priimagi A.: Supramolecular design principles for efficient photoresponsive polymer-azobenzene complexes. Journal of Materials Chemistry C, 6, 2168-2188 (2018). https://doi.org/10.1039/C7TC05005D

[14] Wie J. J., Wang D. H., Lee K. M., Tan L-S., White T. J.: Molecular engineering of azobenzene-functionalized polyimides to enhance both photomechanical work and motion. Chemistry of Materials, 26, 5223-5230 (2014). https://doi.org/10.1021/cm5018757

[15] Wie J. J., Wang D. H., Tondiglia V. P., Tabiryan N. V., Vergara-Toloza R. O., Tan L-S., White T. J.: Photopiezoelectric composites of azobenzene-functionalized polyimides and polyvinylidene fluoride. Macromolecular Rapid Communications, 35, 2050-2056 (2014). https://doi.org/10.1002/marc.201400455

[16] Baczkowski M. L., Wang D. H., Lee D. H., Lee K. M., Smith M. L., White T. J., Tan L-S.: Photomechanical deformation of azobenzene-functionalized polyimides synthesized with bulky substituents. ACS Macro Letters, 6, 1432-1437 (2017). https://doi.org/10.1021/acsmacrolett.7b00854

[17] Shankar M. R., Smith M. L., Tondiglia V. P., Lee K. M., McConney M. E., Wang D. H., Tan L-S., White T. J.: Contactless, photoinitiated snap-through in azobenzene-functionalized polymers. Proceedings of the National Academy of Sciences of the United States of America, 110, 18792-18797 (2013). https://doi.org/10.1073/pnas.1313195110 
[18] Lee K. M., Wang D. H., Koerner H., Vaia R. A., Tan L-S., White T. J.: Enhancement of photogenerated mechanical force in azobenzene-functionalized polyimides. Angewandte Chemie International Edition, B, 41174121 (2012). https://doi.org/10.1002/anie.201200726

[19] Zeng H., Wasylczyk P., Wiersma D. S., Priimagi A.: Light robots: Bridging the gap between microrobotics and photomechanics in soft materials. Advanced Materials, 30, 1703554/1-1703554/9 (2018).

https://doi.org/10.1002/adma.201703554

[20] Wang D. H., Lee K. M., Yu Z., Koerner H., Vaia R. A., White T. J., Tan L-S.: Photomechanical response of glassy azobenzene polyimide networks. Macromolecules, 44, 3840-3846 (2011).

https://doi.org/10.1021/ma200427q

[21] Finkelmann H., Nishikawa E., Pereira G. G., Warner M.: A new opto-mechanical effect in solids. Physical Review Letters, 87, 015501/1-015501/4 (2001).

https://doi.org/10.1103/PhysRevLett.87.015501

[22] Hogan P. M., Tajbakhsh A. R., Terentjev E. M.: UV manipulation of order and macroscopic shape in nematic elastomers. Physical Review E, 65, 041720/1-041720/10 (2002).

https://doi.org/10.1103/PhysRevE.65.041720

[23] Li M-H., Keller P., Li B., Wang X., Brunet M.: Lightdriven side-on nematic elastomer actuators. Advanced Materials, 15, 569-572 (2003). https://doi.org/10.1002/adma.200304552

[24] Camacho-Lopez M., Finkelmann H., Palffy-Muhoray P., Shelley M.: Fast liquid-crystal elastomer swims into the dark. Nature Materials, 3, 307-310 (2004).

https://doi.org/10.1038/nmat1118

[25] Ikeda T., Nakano M., Yu Y., Tsutsumi O., Kanazawa A.: Anisotropic bending and unbending behavior of azobenzene liquid-crystalline gels by light exposure. Advanced Materials, 15, 201-205 (2003). https://doi.org/10.1002/adma.200390045

[26] Ozawa T., Kondo M., Mamiya J-I., Ikeda T.: Enhancement of mechanical stability in hydrogen-bonded photomobile materials with chemically modified singlewalled carbon nanotubes. Journal of Materials Chemistry C, 2, 2313-2315 (2014). https://doi.org/10.1039/C3TC32585G

[27] Yin R., Xu W., Kondo M., Yen C-C., Mamiya J-I., Ikeda T., Yu Y.: Can sunlight drive the photoinduced bending of polymer films? Journal of Materials Chemistry, 19, 3141-3143 (2009).

https://doi.org/10.1039/B904973H

[28] Angiolini L., Benelli T., Giorgini L., Paris F., Salatelli E., Fontana M. P., Camorani P.: Synthesis by ATRP and effects of molecular weight on photomechanical properties of liquid crystalline polymers containing side-chain azobenzene chromophores. European Polymer Journal, 44, 3231-3238 (2008).

https://doi.org/10.1016/j.eurpolymj.2008.07.019
[29] Fang L., Zhang H., Li Z., Zhang Y., Zhang Y., Zhang H.: Synthesis of reactive azobenzene main-chain liquid crystalline polymers via Michael addition polymerization and photomechanical effects of their supramolecular hydrogen-bonded fibers. Macromolecules, 46, 76507660 (2013).

https://doi.org/10.1021/ma401655k

[30] Tabiryan N., Serak S., Dai X-M., Bunning T.: Polymer film with optically controlled form and actuation. Optics Express, 13, 7442-7448 (2005). https://doi.org/10.1364/OPEX.13.007442

[31] van Oosten C. L., Harris K. D., Bastiaansen C. W. M., Broer D. J.: Glassy photomechanical liquid-crystal network actuators for microscale devices. The European Physical Journal E, 23, 329-336 (2007).

https://doi.org/10.1140/epje/i2007-10196-1

[32] Lee K. M., White T. J.: Photochemical mechanism and photothermal considerations in the mechanical response of monodomain, azobenzene-functionalized liquid crystal polymer networks. Macromolecules, 45, 7163-7170 (2012). https://doi.org/10.1021/ma301337e

[33] White T. J.: Photomechanical effects in liquid crystalline polymer networks and elastomers. Journal of Polymer Science Part B: Polymer Physics, 56, 695-705 (2018). https://doi.org/10.1002/polb.24576

[34] Lee J., Oh S., Pyo J., Kim J-M., Je J. H.: A light-driven supramolecular nanowire actuator. Nanoscale, 7, 64576461 (2015).

https://doi.org/10.1039/C5NR01118C

[35] Mamiya J-I.: Photomechanical energy conversion based on cross-linked liquid-crystalline polymers. Polymer Journal, 45, 239-246 (2013).

https://doi.org/10.1038/pj.2012.140

[36] Oscurato S. L., Salvatore M., Maddalena P., Ambrosio A.: From nanoscopic to macroscopic photo-driven motion in azobenzene-containing materials. Nanophotonics, 7, 1387-1422 (2018).

https://doi.org/10.1515/nanoph-2018-0040

[37] Konieczkowska J., Bujak K., Nocoń K., Schab-Balcerzak E.: The large and stable photomechanical effect in the glassy guest-host azopolymers. Dyes and Pigments, 171, 107659/1-107659/7 (2019).

https://doi.org/10.1016/j.dyepig.2019.107659

[38] Eisenbach C. D.: Isomerization of aromatic azo chromophores in poly(ethyl acrylate) networks and photomechanical effect. Polymer, 21, 1175-1179 (1980). https://doi.org/10.1016/0032-3861(80)90083-X

[39] Wie J. J., Wang D. H., Lee K. M., White T. J., Tan L-S.: The contribution of hydrogen bonding to the photomechanical response of azobenzene-functionalized polyamides. Journal of Materials Chemistry C, 6, 5964-5974 (2018). https://doi.org/10.1039/C8TC00319J

[40] Blair H. S., Pague H. I., Riordan J. E.: Photoresponsive effects in azo polymers. Polymer, 21, 1195-1198 (1980). https://doi.org/10.1016/0032-3861(80)90087-7 
[41] Lee K. M., Wang D. H., Koerner H., Vaia R. A., Tan L-S., White T. J.: Photomechanical response of pre-strained azobenzene-functionalized polyimide materials. Macromolecular Chemistry and Physics, 214, 1189-1194 (2013). https://doi.org/10.1002/macp.201200340

[42] Lee K. M., Koerner H., Wang D. H., Tan L-S., White T. J., Vaia R. A.: Tailoring the photomechanical response of glassy, azobenzene-functionalized polyimides by physical aging. Macromolecules, 45, 7527-7534 (2012). https://doi.org/10.1021/ma3016085

[43] Wang D. H., Wie J. J., Lee K. M., White T. J., Tan LS.: Impact of backbone rigidity on the photomechanical response of glassy, azobenzene-functionalized polyimides. Macromolecules, 47, 659-667 (2014). https://doi.org/10.1021/ma402178z

[44] Wie J. J., Chatterjee S., Wang D. H., Tan L-S., Shankar M. R., White T. J.: Azobenzene-functionalized polyimides as wireless actuators. Polymer, 55, 5915-5923 (2014). https://doi.org/10.1016/j.polymer.2014.06.084

[45] Higuchi M., Minoura N., Kinoshita T.: Photo-responsive behavior of a monolayer composed of an azobenzene containing polypeptide in the main chain. Colloid and Polymer Science, 273, 1022-1027 (1995). https://doi.org/10.1007/BF00657668

[46] Hosono N., Yoshikawa M., Furukawa H., Totani K., Yamada K., Watanabe T., Horie K.: Photoinduced deformation of rigid azobenzene-containing polymer networks. Macromolecules, 46, 1017-1026 (2013). https://doi.org/10.1021/ma302157u

[47] Kozanecka-Szmigiel A., Schab-Balcerzak E., Szmigiel D., Konieczkowska J.: The unexpected photomechanical effect in glassy 'T-type' azopolyimides. Journal of Materials Chemistry C, 7, 4032-4037 (2019). https://doi.org/10.1039/C8TC06518G

[48] Li S., Feng Y., Wan W., Ji T., Han J., Long P., Cao C., Feng W.: Polarization-induced alignment of azobenzene/ fluorinated polyimide for three-dimensional shape-persistent and photo-responsive elastic helixes. Composites Science and Technology, 169, 158-166 (2019). https://doi.org/10.1016/j.compscitech.2018.11.014

[49] Yoshino T., Kondo M., Mamiya J-I., Kinoshita M., Yu Y., Ikeda T.: Three-dimensional photomobility of crosslinked azobenzene liquid-crystalline polymer fibers. Advanced Materials, 22, 1361-1363 (2010). https://doi.org/10.1002/adma.200902879

[50] Takashima Y., Hatanaka S., Otsubo M., Nakahata M., Kakuta T., Hashidzume A., Yamaguchi H., Harada A.: Expansion-contraction of photoresponsive artificial muscle regulated by host-guest interactions. Nature Communications, 3, 1270/1-1270/8 (2012).

https://doi.org/10.1038/ncomms2280

[51] van Oosten C. L., Corbett D., Davies D., Warner M., Bastiaansen C. W. M., Broer D. J.: Bending dynamics and directionality reversal in liquid crystal network photoactuators. Macromolecules, 41, 8592-8596 (2008). https://doi.org/10.1021/ma801802d
[52] Oliveira Jr. O. N., dos Santos Jr. D. S., Balogh D. T., Zucolotto V., Mendonça C. R.: Optical storage and surface-relief gratings in azobenzene-containing nanostructured films. Advances in Colloid and Interface Science, 116, 179-192 (2005).

https://doi.org/10.1016/j.cis.2005.05.008

[53] Hu D., Hu Y., Huang W., Zhang Q.: Two-photon induced data storage in hydrogen bonded supramolecular azopolymers. Optics Communications, 285, 4941-4945 (2012). https://doi.org/10.1016/j.optcom.2012.07.115

[54] Konieczkowska J., Schab-Balcerzak E.: Supramolecular azopolymers based on hydrogen bonds (in Polish). Polimery, 60, 3-12 (2015). https://doi.org/10.14314/polimery.2015.425

[55] Koskela E. J., Vappvuori J., Hautala J., Priimagi A., Faul C. H. J., Kaivola M., Ras R. H. A.: Surface-relief gratings and stable birefringence inscribed using light of broad spectral range in supramolecular polymer-bisazobenzene complexes. The Journal of Physical Chemistry C, 116, 2363-2370 (2012).

https://doi.org/10.1021/jp210706n

[56] Eich M., Sen A., Looser H., Bjorklund G. C., Swaien J. D., Twieg R., Yoon D. Y.: Corona poling and realtime second-harmonic generation study of a novel covalently functionalized amorphous nonlinear optical polymer. Journal of Applied Physics, 66, 2559-2567 (1989).

https://doi.org/10.1063/1.344220

[57] Priimagi A., Kaivola M.: Enhanced photoinduced birefringence in polymer-dye complexes: Hydrogen bonding makes a difference. Applied Physics Letters, 90, 121103/1-121103/3 (2007). https://doi.org/10.1063/1.2714292

[58] Natansohn A., Rochon P., Gosselin J., Xie S.: Azo polymers for reversible optical storage. 1. poly[4'-[[2-(acryloyloxy)ethyl]ethylamino]-4-nitroazobenzene]. Macromolecules, 25, 2268-2273 (1992). https://doi.org/10.1021/ma00034a031

[59] Wu S., Duan S., Lei Z., Su W., Zhang Z., Wang K., Zhang Q.: Supramolecular bisazopolymers exhibiting enhanced photoinduced birefringence and enhanced stability of birefringence for four-dimensional optical recording. Journal of Materials Chemistry, 20, 52025209 (2010). https://doi.org/10.1039/C000073F

[60] Konieczkowska J., Kozanecka-Szmigiel A., Piecek W., Węgłowski R., Schab-Balcerzak E.: Azopolyimides - influence of chemical structure on azochromophore photoorientation efficiency. Polimery, 63, 481-487 (2018). https://doi.org/10.14314/polimery.2018.7.1

[61] Bujak K., Kozanecka-Szmigiel A., Schab-Balcerzak E., Konieczkowska J.: Azobenzene functionalized 'T-type' poly(amide imide)s $v s$. guest-host systems - A comparative study of structure-property relations. Materials, 13, 1912/1-1912/16 (2020). https://doi.org/10.3390/ma13081912 
[62] Wang D., Wang X.: Amphiphilic azo polymers: Molecular engineering, self-assembly and photoresponsive properties. Progress in Polymer Science, 38, 271-301 (2013).

https://doi.org/10.1016/j.progpolymsci.2012.07.003

[63] Yaroshchuk O., Reznikov O. Y.: Photoalignment of liquid crystals: Basics and current trends. Journal of Materials Chemistry, 22, 286-300 (2012).

https://doi.org/10.1039/C1JM13485J

[64] Tripathy S. K., Viswanath N. K., Balasubramanian S., Kumar J.: Holographic fabrication of polarization selective diffractive optical elements on azopolymer film. Polymers for Advanced Technologies, 11, 570-574 (2000).

https://doi.org/10.1002/1099-

1581(200008/12)11:8/12<570::AID-PAT7>3.0.CO;2-K

[65] Natansohn A., Rochon P.: Photoinduced motions in azocontaining polymers. Chemical Reviews, 102, 41394176 (2002).

https://doi.org/10.1021/cr970155y
[66] Xue X., Zhu J., Zhang Z., Zhou N., Tu Y., Zhu X.: Soluble main-chain azobenzene polymers via thermal 1,3dipolar cycloaddition: Preparation and photoresponsive behavior. Macromolecules, 43, 2704-2712 (2010). https://doi.org/10.1021/ma902671m

[67] Kim T-D., Lee K-S., Lee G. U., Kim O-K.: Synthesis and characterization of a novel polyimide-based second-order nonlinear optical material. Polymer, 41, 5237-5245 (2000).

https://doi.org/10.1016/S0032-3861(99)00723-5

[68] Skandani A. A., Chatterjee S., Smith M. L., Baranski J., Wang D. H., Tand L-S., White T. J., Shankar M. R.: Discrete-state photomechanical actuators. Extreme Mechanics Letters, 9, 45-54 (2016). https://doi.org/10.1016/j.eml.2016.05.002

[69] Bujak K., Orlikowska H., Małecki J. G., Schab-Balcerzak E., Bartkiewicz S., Bogucki J., Sobolewska A., Konieczkowska J.: Fast dark cis-trans isomerization of azopyridine derivatives in comparison to their azobenzene analogues: Experimental and computational study. Dyes and Pigments, 160, 654-662 (2019). https://doi.org/10.1016/j.dyepig.2018.09.006 